\title{
Helicobacter pylori Antigen in Stool Is Associated With SIDS and Sudden Infant Deaths due to Infectious Disease
}

\author{
ARNE STRAY-PEDERSEN, ÅSHILD VEGE, AND TORLEIV O. ROGNUM \\ Institute of Forensic Medicine, University of Oslo, N-0027 Oslo, Norway
}

\begin{abstract}
Infection with Helicobacter pylori has been proposed to be a common cause of Sudden Infant Death Syndrome (SIDS). We investigated the frequency of $H$. pylori infection in 160 infant deaths and 156 live controls by means of the Helicobacter pylori stool antigen (HpSA) immunoassay. Histology was performed in 26 randomly selected cases. $H$. pylori antigen was detected in $8 \%(12 / 156)$ of the live controls compared with 25\% (30/122) of SIDS cases $(p<$ $0.001), 53 \%(9 / 17)$ of deaths due to infection $(p<0.001)$, and $9 \%$ $(1 / 11)$ of accidental/violent deaths $(p=0.60)$. In the classic age peak for SIDS, $1-5$ mo, 31\% (21/67) of SIDS cases were HpSA positive compared with $1.5 \%(1 / 68)$ of live controls $(p<0.001)$. Rod-like immunoperoxidase positive $H$. pylori organisms were identified in 7/12 HpSA positive gastric antrum sections compared with 2/14 HpSA negative $(p=0.038)$. Significantly elevated IL-6 levels in cerebrospinal fluid representing signs of central immune stimulation were demonstrated in HpSA positive SIDS victims compared with HpSA negative victims $(p=0.045)$. Detection of $H$. pylori antigen in stool is associated with SIDS and deaths due to infections. We hypothesize that $H$. pylori infection in infancy may be involved as the triggering pathogen for sudden death during the first 5 month after birth. (Pediatr Res 64: 405-410, 2008)
\end{abstract}

$\mathrm{I}$ nfection with Helicobacter pylori is involved in the pathogenesis of acute gastritis and peptic ulcers and is associated with gastric adenocarcinoma and MALT lymphoma (1). In recent years, a variety of extradigestive disorders, including cardiovascular diseases, autoimmune disorders, and liver diseases have also been associated with $H$. pylori infection (2). In 1997, a possible link between H. pylori and Sudden Infant Death Syndrome (SIDS) was hypothesized (3). In a casecontrol study, Kerr et al. (4) reported a highly significant association between the detection of $H$. pylori DNA sequences in various organ tissues and SIDS. The study was, however, heavily debated and criticized for design and methodology (5). Later case-control studies have failed to confirm a role for $H$. pylori in SIDS (6-8).

The incidence of SIDS dropped dramatically following the intervention programs directed against prone sleeping and smoking in pregnancy, however the underlying mechanism involved in SIDS still remains unknown. Disturbed homeostasis of the immune system as a response to infection in the aerodigestive tract may play a role as trigger event for the

Received for publication February 26, 2008; accepted April 26, 2008.

Correspondence: Arne Stray-Pedersen, M.D., Institute of Forensic Medicine, University of Oslo, Rikshospitalet, N-0027 Oslo, Norway; e-mail: arne.stray-pedersen@medisin. uio.no

Supported by the aid of EXTRA funds from the Norwegian Foundation for Health and Rehabilitation and with grants from the Norwegian SIDS Society. death mechanism in a large proportion of the SIDS cases $(9,10)$. Increased concentrations of IL-6 in cerebrospinal fluid (CSF) have been found in SIDS victims (11), and elevated IL-6 levels is found to be associated with immunoreactivity in the larynx and with symptoms of cold before death (12). Mucosal immune activation in the duodenum has also been shown in SIDS (13). Epidemiologic studies have disclosed that SIDS is associated with symptoms of cold before death, winter season, and occurrence of respiratory epidemic infections $(14,15)$.

We have recently presented a study of the prevalence of $H$. pylori stool antigen (HpSA) in healthy Norwegian infants (16). In this follow-up study, we have investigated the frequency and significance of $H$. pylori infection in SIDS victims and other sudden unexpected infant deaths.

\section{METHODS AND MATERIALS}

Subjects. The study population consisted of 160 cases of sudden unexpected deaths in infancy (SUDI) below $1 \mathrm{y}$ of age (boys/girls $=96 / 64)$ from the southeastern region of Norway investigated at the Institute of Forensic Medicine in Oslo between 1993 and 2004. Only infants of ethnic Nordic citizens were included in the study. The postmortem investigation involved evaluation of circumstances of death, review of medical and family history, full-body radiographical examination, toxicology, and a thorough autopsy with extensive histologic and microbiological examinations, including neuropathological examination. Autopsies were performed by the same forensic pathologists ( $\mathrm{V}$, TOR, MAR, ASP); median time interval from death to autopsy was $19 \mathrm{~h}$ (range 5-77). Based on the Nordic SIDS criteria $(17,18)$, the cases were categorized as either pure SIDS (no cause of death revealed), borderline SIDS (significant, yet nonlethal findings revealed), or explained deaths (Table 1). The latter were categorized as violent deaths, infectious deaths, or deaths due to noninfectious disease (Table 1). The control group consisted of 156 healthy children (boys/girls $=75 / 81$ ) from the South-eastern part of Norway, recruited by consecutive sampling in two maternity clinics (Marienlyst, city of Drammen and Frogn, City of Drobak) from Oct 2003 to Nov 2004 and has been presented in detail previously (16). Informed consent was obtained from the parents. The study was approved by the Committee for Medical Research Ethics in Norway.

Sample collection and preparation. Stool specimens from the controls were collected from the diapers upon admission to the maternity clinic, as described previously (16). From the patients, stool specimens were obtained during autopsy by a "milking procedure" of the dissected rectal colon. Specimens were stored at $-80^{\circ} \mathrm{C}$ before analysis. Samples of cerebrospinal fluid were obtained by suboccipital puncture. Gastric antrum tissue specimens were also obtained during autopsy, fixed directly in cold ethanol, and embedded in paraffin.

HpSA ELISA. For detection of H. pylori, the Premier Platinum H. pylori stool antigen ELISA kit, HpSA (Meridian Bioscience Inc., Ohio, USA), was

Abbreviations: CSF, cerebrospinal fluid; $\mathbf{H} \& \mathbf{E}$, hematoxylin and eosin staining; HpSA, Helicobacter pylori stool antigen; H. pylori, Helicobacter pylori; IL-6, interleukin-6; SIDS, sudden infant death syndrome; SUDI, sudden unexpected death in infancy 
Table 1. HpSA detection rate and classification of subjects investigated

\begin{tabular}{|c|c|c|c|c|c|}
\hline Category & No & $\begin{array}{l}\text { Sex } \\
\mathrm{M} / \mathrm{F}\end{array}$ & $\begin{array}{c}\text { Age in days } \\
\text { median (range) }\end{array}$ & $H p S A$ positive & $p$-value* \\
\hline SIDS & 83 & $48 / 35$ & $111(7-323)$ & $17(20 \%)$ & 0.004 \\
\hline Borderline SIDS & 39 & $25 / 14$ & $76(11-287)$ & $13(33 \%)$ & $<0.001$ \\
\hline 16 slight infection & & & & 5 & \\
\hline 14 nonlethal conditions & & & & 5 & \\
\hline 9 circumstances of death & & & & 3 & \\
\hline Infectious deaths & 17 & $15 / 2$ & $91(15-357)$ & $9(53 \%)$ & $<0.001$ \\
\hline 9 pneumonia & & & & 5 & \\
\hline 3 septicemia & & & & 1 & \\
\hline 5 other (meningitis, myocarditis, peritonitis) & & & & 3 & \\
\hline Non-infectious disease & 10 & $1 / 9$ & $95(7-345)$ & $2(20 \%)$ & 0.20 \\
\hline 4 heart failure (malformations) & & & & 1 & \\
\hline 2 lung failure (malformation and immaturity) & & & & 0 & \\
\hline 2 epilespy (birth-related cerebral injury) & & & & 0 & \\
\hline 1 inborn immunodeficency (DiGiorge syndr.) & & & & 0 & \\
\hline 1 Ileus/peritonitis (Meckels diverticulum) & & & & 1 & \\
\hline Accidental/inflicted death & 11 & $7 / 4$ & $200(9-333)$ & $1(9 \%)$ & 0.60 \\
\hline 6 asphyxic deaths & & & & 1 & \\
\hline 4 head injury & & & & 0 & \\
\hline 1 starvation/dehydration & & & & 0 & \\
\hline Live infants & 156 & $75 / 81$ & $75(8-360)$ & $12(8 \%)$ & \\
\hline Total & 316 & $171 / 145$ & $90(7-360)$ & $54(17 \%)$ & \\
\hline
\end{tabular}

* Chi-squared analysis compared to live control infants.

performed according to the instructions of the manufacturer. Briefly, diluted stool samples were incubated in microwells coated with rabbit antibodies recognizing $H$. pylori antigens and then with rabbit anti- $H$. pylori antibody conjugate in the presence of color developing solution. The OD values were determined at $450 \mathrm{~nm}$ wavelength. Tests were regarded positive when OD $\geq$ 0.160 . All samples were tested twice using separate test tubes and blinded for diagnosis.

Histology and immune staining. Gastric antrum tissue specimens from 30 randomly chosen cases (first $15 \mathrm{HpSA}$ positive and first 15 age-matched negative cases in the dataset) were fixed directly in cold ethanol and embedded in paraffin. Parallel sections were cut at $4 \mu \mathrm{m}$ and either stained with hematoxylin and eosin (H \& E), Giemsa or mounted on clean polysine slides and processed for immune staining: Dried, deparaffined and rehydrated slides were subjected to pretreatment with Proteinase $\mathrm{K}$ for $8 \mathrm{~min}$ and incubated with ChemMate Peroxidase Blocking Solution in room temperature for 10 min. The slides were subsequently incubated with the polyclonal rabbit anti-H. pylori antibodies (Dilution 1:40, Batch B-0471, DAKO, Glostrup, Denmark) for $30 \mathrm{~min}$ at room temperature. Immunostaining was performed with the ChemMate EnVision Detection Kit Peroxidase/DAB Rb/Mo (K5007; DAKO); incubation with polymer for $30 \mathrm{~min}$, incubation with substrate for 5 min and toning in $0.5 \%$ copper sulfate for $5 \mathrm{~min}$ at room temperature. Counterstaining was finally briefly performed with hematoxylin.

The tissue sections were evaluated blindly by a specialist in microbiology and pathology ( $\AA \mathrm{V}$ ) who had no information about case history or stool test findings. Four sections ( $3 \mathrm{HpSA}$ positive and $1 \mathrm{HpSA}$ negative) were ineligible for evaluation due to technical errors in the paraffin embedding. $\mathrm{H} \& \mathrm{E}$ stains of the remaining 26 sections were reviewed and semiquantitated for degree of autolysis and chronic and active inflammation. Giemsa and immunoperoxidase stains were reviewed at high $(630 \times)$ power light microscopy for the presence of $H$. pylori in the surface mucous layer and within gland crypts of the lamina propria. Tissue sections were reevaluated blindly by the same observer and the reproducibility was good having the same result in 24 of 26 reexamined cases.

IL-6 measurement. IL-6 concentrations in CSF were measured by an ELISA kit (R\&D Systems Inc., Minneapolis, USA), utilizing $100 \mu \mathrm{L}$ CSF and performed with OD determination as previously described (12).

Microbial cultures. In all patients investigated in this study, microbial aerobic/anaerobic cultures of blood and CSF as well as organ tissues of lung, liver, spleen, and kidney were taken at autopsy. To disclose possible associations between $H$. pylori antigen detection and other bacteria, the culture reports from the infectious deaths $(n=17)$ and the borderline SIDS cases with possible infection $(n=16)$ were investigated.

Statistical analyses. The $\chi^{2}$ analysis was used for comparison of categorical variables between groups. When the expected values were $<5$, the Fisher's exact test was applied. The Mann-Whitney U-test was used for comparison of continuous variables. The significance level was set at values of $p<0.05$.

\section{RESULTS}

H. pylori stool antigen in cases and controls. H. pylori antigen in stool was detected in 53\% of infants who died due to an infectious disease, and 25\% of the SIDS cases (pure and borderline SIDS conjoined), compared with $8 \%$ of the agematched live control infants ( $p<0.001$ for both groups) (Table 1). Furthermore, positive HpSA tests were found in $20 \%(p=0.20)$ of the deaths due to noninfectious disease and in $9 \%$ of the violent deaths $(p=0.60)$.

Histology. Examination of histology was problematic due to tissue autolysis (Table 2). The foveolar epithelium and covering mucus-layer were partially or totally lost. Presence of both rods and coccoid bacteria were detected in 50\% $(13 / 26)$ of specimen. Scattered curved and rod-like structures stained positive by specific immune staining were observed, localized on the luminal side of foveolar epithelial cells, and in glandular crypts (Fig. 1). The pathologist, who was unaware of the HpSA results, confirmed the presence of $H$. pylori bacteria in 7/12 gastric specimen of HpSA positive infants compared with $2 / 14$ HpSA negative $(p=0.038)$ (Table 2$)$. No signs of acute inflammation were observed in any of the sections investigated, but in five of the cases a few foci with lymphocytes in the basal layer of the mucosa were observed, however not related to positive immune staining (Table 2).

H. pylori and epidemiologic variables. Twenty-six percent (24/92) of SIDS victims below 6 mo of age were HpSA positive, compared with $7 \%(2 / 30)$ of SIDS victims in the second half year of infancy $(p=0.24)$. In the classic peak age group, $1-5$ mo, $31 \%(21 / 67)$ of the SIDS cases were HpSA positive compared with $1.5 \%(1 / 68)$ of the live controls $(p<$ 0.001) (Fig. 2). Looking at all infant deaths, a significantly higher proportion of the infants dying in the cold season were HpSA positive, compared with those who died in the summer season (33\% (30/90) and 17\% (12/70), respectively, $p=$ 0.021 ). In the live controls, no difference was found between 
Table 2. Histology examination of 26 cases of sudden death in infancy

\begin{tabular}{|c|c|c|c|c|c|c|c|c|}
\hline \multirow{2}{*}{$\begin{array}{c}\text { Cause of } \\
\text { death }\end{array}$} & \multirow[b]{2}{*}{ Sex } & \multirow{2}{*}{$\begin{array}{l}\text { Age } \\
(\mathrm{mo})\end{array}$} & \multicolumn{3}{|c|}{ HE staining } & \multirow[b]{2}{*}{ Giemsa } & \multirow{2}{*}{$\begin{array}{l}\text { Hp immune } \\
\text { staining }\end{array}$} & \multirow{2}{*}{$\begin{array}{c}\text { HpSA stool } \\
\text { test }\end{array}$} \\
\hline & & & Autolysis* & Inflammation** & Bacteria & & & \\
\hline SIDS & M & 1 & $(+)$ & ++ & Rods and cocci & Rods and cocci & pos & pos \\
\hline SIDS & $\mathrm{F}$ & 1 & +++ & + & Rods and cocci & Rods and cocci & pos & pos \\
\hline SIDS & $\mathrm{F}$ & 2 & +++ & + & Rods and cocci & Rods and cocci & pos & pos \\
\hline SIDS & M & 2 & +++ & + & - & Rods & pos & pos \\
\hline SIDS & M & 3 & ++ & + & - & Rods & pos & pos \\
\hline Pneumonia & M & 4 & + & + & Rods and cocci & Rods and cocci & pos & pos \\
\hline Pneumonia & $\mathrm{F}$ & 3 & ++ & + & Rods & Rods and cocci & pos & pos \\
\hline SIDS & M & 4 & + & + & Rods & Rods & pos & neg \\
\hline SIDS & $\mathrm{F}$ & 2 & + & + & - & Rods and cocci & pos & neg \\
\hline SIDS & $\mathrm{F}$ & 1 & + & + & Rods and cocci & Rods and cocci & neg & pos \\
\hline SIDS & $\mathrm{F}$ & 2 & +++ & + & Rods & Rods & neg & pos \\
\hline Lung failure & $\mathrm{F}$ & 1 & +++ & + & Rods and cocci & Rods and cocci & neg & pos \\
\hline Septicemia & M & 11 & +++ & + & Rods & Rods & neg & pos \\
\hline Pneumonia & M & 3 & + & ++ & - & Rods & neg & pos \\
\hline SIDS & $\mathrm{F}$ & 1 & +++ & ++ & Rods and cocci & Rods and cocci & neg & neg \\
\hline SIDS & M & 1 & +++ & + & Rods and cocci & Rods and cocci & neg & neg \\
\hline SIDS & M & 3 & + & + & Rods and cocci & Rods and cocci & neg & neg \\
\hline SIDS & M & 9 & +++ & + & Rods and cocci & Rods and cocci & neg & neg \\
\hline SIDS & M & 4 & ++ & + & - & Rods and cocci & neg & neg \\
\hline SIDS & $\mathrm{F}$ & 1 & +++ & + & Rods & Rods & neg & neg \\
\hline SIDS & M & 1 & +++ & + & Rods & Rods & neg & neg \\
\hline SIDS & $\mathrm{F}$ & 2 & ++ & + & Rods & Rods & neg & neg \\
\hline SIDS & M & 5 & +++ & + & - & - & neg & neg \\
\hline Accidental & M & 5 & ++ & ++ & Rods & Rods & neg & neg \\
\hline Accidental & $\mathrm{F}$ & 8 & +++ & + & Rods & Rods & neg & neg \\
\hline Accidental & M & 8 & +++ & ++ & Rods & Rods & neg & neg \\
\hline
\end{tabular}

* Degree of autolysis: [+] areas with some preserved surface and foveolar epithelium, gland crypts well preserved; [++] most foveolar epithelium lost, gland crypts present; $[+++]$ all superficial and foveolar compartment lost. Only basal layers of gland crypts present.

** Degree of inflammation: $[+]$ scattered inflammatory cells; $[++]$ one or a few foci with inflammatory cells; $[+++]$ severe inflammation.

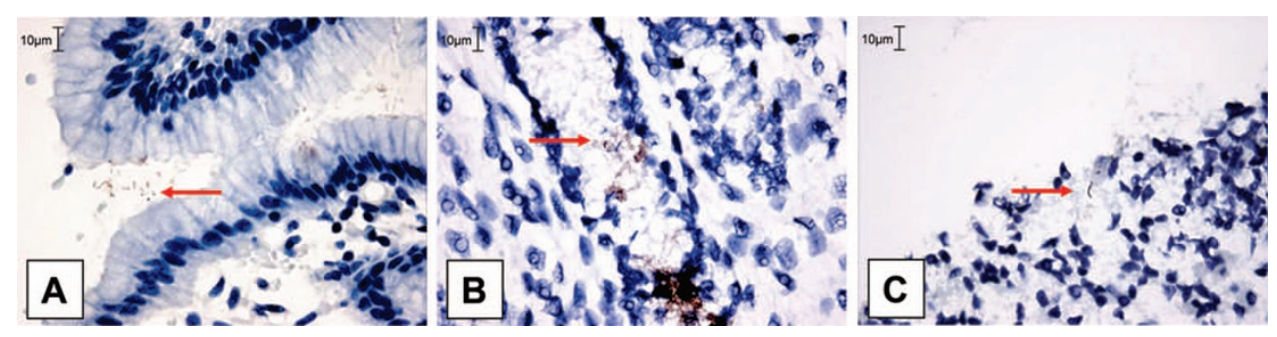

Figure 1. Photomicrographs $(450 \times)$ of anti-H. pylori immunoperoxidase staining in gastric tissue. A: positive control. B-C: cases of SIDS. Red arrows point at curved and rod-like structures with positive immune staining (H. pylori bacteria).

stool samples collected in the winter season, 9\% (8/92) and in the summer season, $6 \%(4 / 64), p=0.57$. Other epidemiologic factors for SIDS, such as male gender, prone sleeping position, or bed sharing did not show any association with the HpSA findings (Table 3).

H. pylori and microbial cultures. Pathogens of possible significance (i.e., pure growth of streptococci, Klebsiella pneumonia, staphylococci, or enterococci) growing in CSF and/or heart blood specimens were detected in 12 out of 33 cases of infant deaths classified as due to infection or as borderline SIDS with signs of infection insufficient to explain the cause of death. Forty-two percent of the cases with findings of such pathogens were HpSA positive, compared with $38 \%$ of the cases without ( $p=0.8$ N.S.).

H. pylori and IL-6. IL-6 concentrations in CSF were measured in 147/160 infant deaths. In HpSA positive cases, the IL-6 levels were significantly higher (median $32 \mathrm{pg} / \mathrm{mL}$; interquartile range (IQR) 153) compared with HpSA negative cases (median $9 \mathrm{pg} / \mathrm{mL}$; IQR 32, $p=0.006$ ) (Fig. 3). The difference was also significant for SIDS tested separately: Median IL-6 levels in HpSA positive and negative SIDS cases were $28 \mathrm{pg} / \mathrm{mL}$ (IQR 153) and $10 \mathrm{pg} / \mathrm{mL}$ (IQR 33), respectively $(p=0.047)$.

\section{DISCUSSION}

In 1997, Pattison and Marshall (3) put forward the hypothesis of a possible relationship between $H$. pylori infection and SIDS. They hypothesized that aspiration of gastric juice containing large amounts of urease from $\mathrm{H}$. pylori, could react with plasma urea to produce ammonia toxicity and cause respiratory arrest. Three years later, Kerr et al. (4) detected $H$. pylori DNA sequences by means of PCR in 28 of 32 SIDS cases compared with only one of 8 controls and concluded that a causative role for H. pylori in SIDS was likely. The study was heavily debated (5), but was followed by only a few small-number studies, which were unable to confirm Kerr's results $(6,8,19)$. Elitsur et al. (8) investigated 25 SIDS cases 


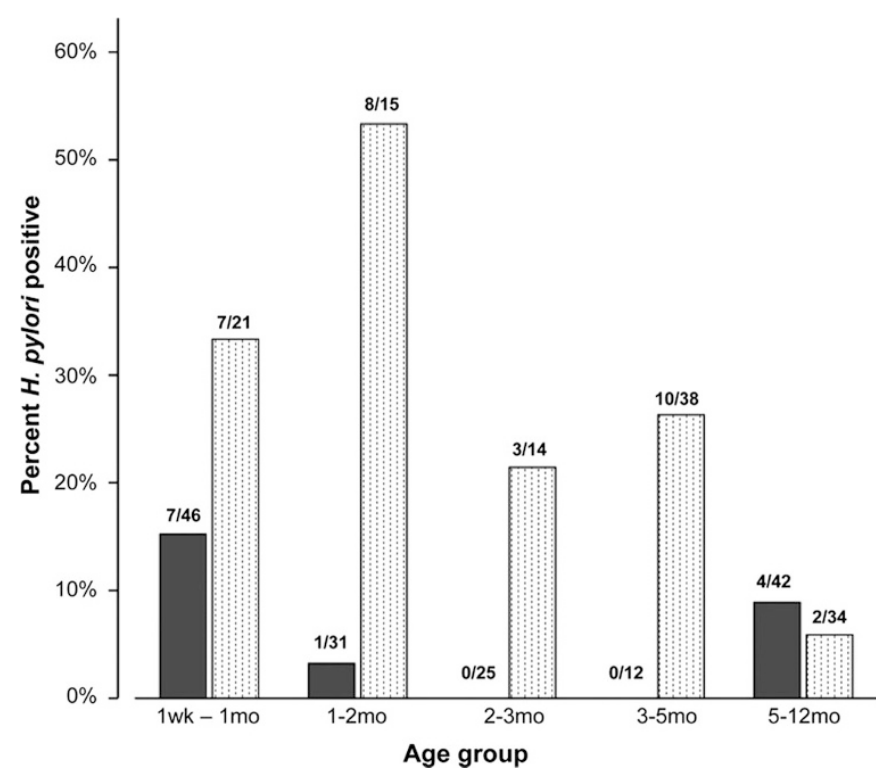

Figure 2. H. pylori antigen detection rate in SIDS* (white dotted columns) and live control infants (shaded columns) at different age groups. *Both pure SIDS and borderline SIDS are included.

and detected $H$. pylori DNA in gastric or tracheal specimen from six of these cases. The presence of $H$. pylori organisms was, however, not confirmed by histology or immunohistochemistry. Ho et al. (6) detected H. pylori DNA by PCR in gastric tissue samples in 54\% (9/17) of SIDS cases and 57\% (4/7) of controls, but were unable to confirm the results by urease test, bacterial culture, or immunohistochemical methods. Recently, Loddenkötter et al. (7) investigated gastric tissue specimen from 94 cases of SIDS with an accurate PCR technique, finding traces of the $H$. pylori specific ureC gene in only two of these cases. In conclusion, though H. pylori DNA has been detected by PCR in gastric or respiratory tissue to a variable extent, only Kerr's study is supportive of an association between $H$. pylori and SIDS. Moreover, H. pylori infection has not been documented histopathologically in SIDS in any of the studies.

The present study is the first to investigate stool specimens, demonstrating a significant association between the presence of $H$. pylori stool antigen and sudden infant deaths. The method of choice, the HpSA test, is a well-recognized proce-

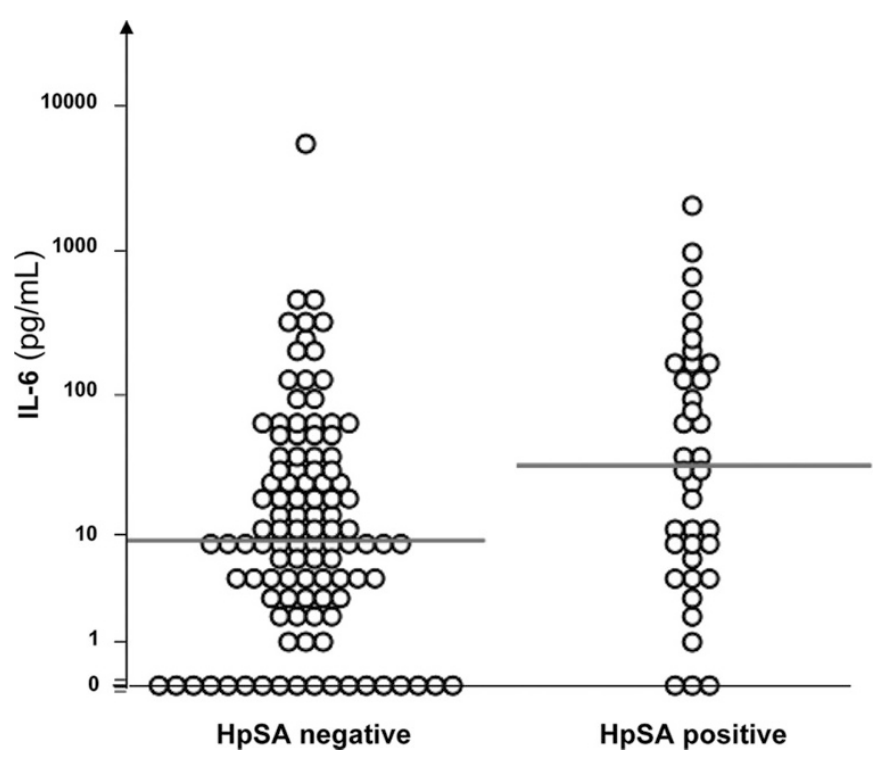

Figure 3. Cerebrospinal fluid IL-6 concentrations in HpSA negative and positive cases of sudden deaths in infancy (SUDI). Horizontal lines represent median IL-6 levels in the two groups, 9 and $32 \mathrm{pg} / \mathrm{mL}$ respectively $(p=0.006)$.

dure for detecting $H$. pylori infection in pediatric populations $(20,21)$, utilizing polyclonal antibodies that target $H$. pylori specific proteins. Although a monoclonal kit has now been introduced by the manufacturer, the HpSA kit has been widely used and a high diagnostic accuracy has been described in both high and low prevalence groups $(20,21)$. In the Nordic countries, the prevalence of $H$. pylori infection in children is most likely very low $(16,22)$. The low frequency of HpSA positive tests in our controls (8\%) thus favors the reliability of the test. Correspondingly, the fact that only one of 11 infants (9\%) in the group of accidental deaths were HpSA positive yields an indication that the test behaves similarly in stool samples from live and dead infants.

Comparing SIDS with other subclasses of SUDI is complicated. Infants that die suddenly and unexpectedly due to an infection or other disease are likely, in some manner, to be predisposed to the fatal outcome. Accidental deaths rarely occur in infancy, but the age distribution is different from in SIDS (Table 1). Epidemiologic risk factors for SIDS like maternal smoking, winter seasonality and social deprivation

Table 3. Epidemiological variables and autopsy findings in HpSA positive and negative SIDS* cases

\begin{tabular}{|c|c|c|c|c|c|}
\hline & \multicolumn{2}{|c|}{ HpSA positive } & \multicolumn{2}{|c|}{ HpSA negative } & \multirow[b]{2}{*}{$p$-value } \\
\hline & Mean & $\mathrm{N}=30$ & Mean & $\mathrm{N}=92$ & \\
\hline Male gender & $53 \%$ & $(16 / 30)$ & $62 \%$ & $(57 / 92)$ & 0.40 \\
\hline Cold season & $67 \%$ & $(20 / 30)$ & $50 \%$ & $(46 / 92)$ & 0.11 \\
\hline Prone sleeping & $40 \%$ & $(10 / 25)$ & $60 \%$ & $(47 / 78)$ & 0.08 \\
\hline Bed sharing & $39 \%$ & $(11 / 28)$ & $32 \%$ & $(29 / 91)$ & 0.47 \\
\hline Cold at time of death & $45 \%$ & $(10 / 22)$ & $30 \%$ & $(23 / 77)$ & 0.17 \\
\hline Fever at time of death & $16 \%$ & $(3 / 19)$ & $7 \%$ & $(5 / 71)$ & 0.36 \\
\hline Maternal smoking & $65 \%$ & $(11 / 17)$ & $65 \%$ & $(32 / 49)$ & 0.96 \\
\hline Intrathoracic petechia & $67 \%$ & $(20 / 30)$ & $72 \%$ & $(66 / 92)$ & 0.60 \\
\hline Age at time of death** & 63 days & & 112 days & & 0.003 \\
\hline Maternal age** & $23.5 \mathrm{yr}$ & & $26.0 \mathrm{yr}$ & & 0.28 \\
\hline
\end{tabular}

* SIDS and borderline SIDS conjoined.

** Age presented with median values. 
are not restricted to SIDS, but are also associated with other natural causes of sudden infant death (23). On the other hand, except for the variability of $H$. pylori detection with age, no associations were found between $H$. pylori status and epidemiologic factors (Table 3). Unfortunately, the dataset did not include sufficient information with regard to socio-economic status to enable valid comparison analyses. Thus, it cannot entirely be ruled out whether the higher incidence of $H$. pylori detection rate in SIDS and deaths due to infections reflects lower hygienic standards. However, the socio-economic imbalance is less pronounced in Norway than in other western countries and in a previous study from the same region, Arnestad et al. (24) were unable to find a difference in socio-economic status between SIDS and age-matched live controls.

Acute infection with $H$. pylori does not necessarily result in chronic infection $(25,26)$. Serological studies indicate that particularly the acquisition of $H$. pylori infection in early infancy is associated with a high rate of subsequent loss of bacteria $(22,27)$. We recently reported a high proportion of HpSA positive stool samples in healthy Norwegian newborn infants delivered vaginally (16). The unanticipated result was confirmed by the detection of $H$. pylori DNA by PCR in several of the samples. We hypothesized that $H$. pylori transmission from mother to child is likely to occur during the baby's passage through the birth canal. On the other hand, the $\mathrm{HpSA}$ detection rate in infants older than 1 week of age is low. Thus, in most normal individuals the encounter with $H$. pylori does not seem to result in a permanent colonization of the gastric mucosa. Development of chronic infection and H. pylori related disease is determined by host-pathogen interactions (25). The significance of $H$. pylori virulence factors has been widely studied (28), but individual susceptibility and environmental factors probably play an equally important role (29). Polymorphisms in host genes that encode immune modulating factors have been shown to affect $H$. pylori related diseases (30). Wu et al. found that IL-10 polymorphisms and smoking were individual risk factors for the development of gastric cancer. Interestingly, the most important environmental risk factor for SIDS after prone sleeping is maternal smoking (24) and IL-10 polymorphisms (31) have also been implicated in SIDS and sudden infant deaths due to infectious disease.

There is a discrepancy between our findings and previous studies that have investigated gastric specimen from SIDS by immunohistochemical methods. Neither Elitsur et al. (8) or Ho et al. (6) identified $H$. pylori-like organisms in any of the samples investigated. On conventional H \& E stained gastric tissue sections, Ho et al. (6) reported occasional thick rods and clusters of cocci, but no curved rod-like bacteria characteristic of $H$. pylori. Immunoperoxidase staining gave also negative results. Unavoidably, postmortem gastric tissue is subject to autolysis shortly after death. In our material, the presence of rod-like $H$. pylori positive stained structures was scarce and void of inflammatory changes in the surrounding mucosa. A majority of the tissue samples were collected during autopsy performed within $24 \mathrm{~h}$ after death. However, manifest autolysis was observed in almost all of the sections. Thus, inflammatory changes may have been present before death in several of the cases, although we may have been unable to detect it due to tissue autolysis.

The drop in SIDS rate following the intervention programs directed against prone sleeping and smoking in pregnancy, predominantly involved young infants between 1 and 5 mo of age, whereas older infants were less affected (14). The mucosal immunity is developing rapidly during the first months of life (32-34) and an activation of mucosal immunity in the aerodigestive tract has been demonstrated in SIDS victims $(13,35)$. In the present study detection of $H$. pylori stool antigen also varied significantly with age; cases below 5 mo of age being accountable for the difference between SIDS and live controls. The HpSA results from the youngest SIDS cases were comparable to the group of infectious deaths, whereas the results from the SIDS cases older than 5 mo of age were similar to the live controls (Fig. 2). The highest $H$. pylori detection rate was found among infants that died suddenly and unexpectedly due to infections. We postulate that $H$. pylori infection in infancy in a Norwegian population represent a biomarker of increased vulnerability to infections and increased risk for sudden death before 5 mo of age. We have previously reported that a significant proportion of SIDS cases have elevated CSF levels of the pro-inflammatory cytokine IL-6, produced in response to microbial products (36), analogous to infants that died due to infection (11). Disturbances in the immunologic homeostasis caused by a combination of genetic predisposition, vulnerable developmental stage, and a trigger event may induce the death mechanism in a large proportion of SIDS cases $(9,10,37)$. Such a trigger event may be a slight infection with stimulation of the mucosal immune system (9). The association between $H$. pylori detection and central immune stimulation may indicate that $H$. pylori may be involved as the triggering pathogen.

Acknowledgments. The authors thank Musse Ahmed Musse and Hang Duong for technical assistance.

\section{REFERENCES}

1. Versalovic J 2003 H. pylori. Pathology and diagnostic strategies. Am J Clin Pathol 119:403-412

2. Franceschi F, Gasbarrini A 2007 H. pylori and extragastric diseases. Best Pract Res Clin Gastroenterol 21:325-334

3. Pattison CP, Marshall BJ 1997 Proposed link between H. pylori and sudden infant death syndrome. Med Hypotheses 49:365-369

4. Kerr JR, Al Khattaf A, Barson AJ, Burnie JP 2000 An association between sudden infant death syndrome (SIDS) and H. pylori infection. Arch Dis Child 83:429-434

5. Koletzko S, Konstantopoulos N, Lehn N, Forman D 2001 Control your controls and conclusions. Arch Dis Child 84:525

6. Ho GY, Windsor HM, Snowball B, Marshall BJ $2001 \mathrm{H}$. pylori is not the cause of sudden infant death syndrome (SIDS). Am J Gastroenterol 96:3288-3294

7. Loddenkötter B, Becker K, Hohoff C, Brinkmann B, Bajanowski T 2005 Real-time quantitative PCR assay for the detection of $H$. pylori: no association with sudden infant death syndrome. Int J Legal Med 119:202-206

8. Elitsur Y, Btriest W, Sabet Z, Neace C, Jiang C, Thomas E 2000 Is sudden infant death syndrome associated with $H$. pylori infection in children? Helicobacter 5:227-231

9. Rognum TO, Byard RW 2005 Sudden Infant death syndrome, etiology and epidemiology. In: Payne-James J, Byard RW, Corey T, Henderson C (eds) Encyclopedia of Forensic and Legal Medicine. Amsterdam: Elsevier, pp 117-127

10. Rognum TO, Saugstad OD 1993 Biochemical and immunological studies in SIDS victims. Clues to understanding the death mechanism. Acta Paediatr Suppl 82:82-85

11. Vege A, Rognum TO, Scott H, Aasen AO, Saugstad OD 1995 SIDS cases have increased levels of interleukin-6 in cerebrospinal fluid. Acta Paediatr 84:193-196

12. Vege A, Rognum TO, Anestad G 1999 IL-6 cerebrospinal fluid levels are related to laryngeal IgA and epithelial HLA-DR response in sudden infant death syndrome. Pediatr Res 45:803-809 
13. Stoltenberg L, Saugstad OD, Rognum TO 1992 Sudden infant death syndrome victims show local immunoglobulin $\mathrm{M}$ response in tracheal wall and immunoglobulin A response in duodenal mucosa. Pediatr Res 31:372-375

14. Vege A, Rognum TO, Opdal SH 1998 SIDS-changes in the epidemiological pattern in eastern Norway 1984-1996. Forensic Sci Int 93:155-166

15. Lindgren C, Milerad J, Lagercrantz H 1997 Sudden infant death and prevalence of whooping cough in the Swedish and Norwegian communities. Eur J Pediatr 156:405-409

16. Stray-Pedersen A, Gaustad P, Stray-Pedersen B, Rognum TO 2007 Detection rate of H. pylori stool antigen in newborn infants and small children. J Perinat Med 35: $155-158$

17. Gregersen M, Rajs J, Laursen H, Baandrup U, Frederiksen P, Gidlund E 1995 Pathologic criteria for the Nordic study of SIDS. In: Rognum TO (ed) Sudden Infant Death Syndrome New Trends in the Nineties. Oslo: Scandinavian University Press, pp 50-58

18. Stray-Pedersen A, Rognum TO 2004 Evaluation of circumstances and clinical history in SUDI. Scand J Forens Sci 10:77-79

19. Dubos F, Gottrand F, Devisme L, Carpentier C 2003 The end of H. pylori as a hypothetic cause of SIDS. Am J Gastroenterol 98:1206-1207

20. Malfertheiner P, Megraud F, O'Morain C, Bazzoli F, El-Omar E, Graham D, Hunt R, Rokkas T, Vakil N, Kuipers EJ 2007 Current concepts in the management of $H$. pylori infection: the Maastricht III Consensus Report. Gut 56:772-781

21. Konstantopoulos N, Russmann H, Tasch C, Sauerwald T, Demmelmair H, Autenrieth I, Koletzko S 2001 Evaluation of the H. pylori stool antigen test (HpSA) for detection of $H$. pylori infection in children. Am J Gastroenterol 96:677-683

22. Granstrom M, Tindberg Y, Blennow M 1997 Seroepidemiology of H. pylori infection in a cohort of children monitored from 6 months to 11 years of age. J Clin Microbiol 35:468-470

23. Vennemann M, Bajanowski T, Butterfass-Bahloul T, Sauerland C, Jorch G, Brinkmann B, Mitchell EA 2007 Do risk factors differ between explained sudden unexpected death in infancy and sudden infant death syndrome? Arch Dis Child 92:133-136

24. Arnestad M, Andersen M, Vege A, Rognum TO 2001 Changes in the epidemiological pattern of sudden infant death syndrome in southeast Norway 1984-1998: implications for future prevention and research. Arch Dis Child 85:108-115
25. Delport W, van der Merwe SW 2007 The transmission of H. pylori: the effects of analysis method and study population on inference. Best Pract Res Clin Gastroenterol 21:215-236

26. Kivi M, Tindberg Y 2006 H. pylori occurrence and transmission: a family affair? Scand J Infect Dis 38:407-417

27. Malaty HM, El Kasabany A, Graham DY, Miller CC, Reddy SG, Srinivasan SR, Yamaoka Y, Berenson GS 2002 Age at acquisition of $H$. pylori infection: a follow-up study from infancy to adulthood. Lancet 359:931-935

28. Andersen LP 2007 Colonization and Infection by H. pylori in Humans. Helicobacter $12: 12-15$

29. van Amsterdam K, van Vliet AH, Kusters JG, van der Ende A 2006 Of microbe and man: determinants of $H$. pylori-related diseases. FEMS Microbiol Rev 30:131-156

30. El-Omar EM, Carrington M, Chow WH, McColl KE, Bream JH, Young HA, Herrer J, Lissowska J, Yuan CC, Rothman N, Lanyon G, Martin M, Fraumeni JF Jr., Rabkin CS 2000 Interleukin-1 polymorphisms associated with increased risk of gastric cancer. Nature 404:398-402

31. Opdal SH, Opstad A, Vege A, Rognum TO 2003 IL-10 gene polymorphisms are associated with infectious cause of sudden infant death. Hum Immunol 64:1183-1189

32. Rognum TO, Thrane S, Stoltenberg L, Vege A, Brandtzaeg P 1992 Development of intestinal mucosal immunity in fetal life and the first postnatal months. Pediatr Res 32:145-149

33. Stoltenberg L, Thrane PS, Rognum TO 1993 Development of immune response markers in the trachea in the fetal period and the first year of life. Pediatr Allergy Immunol 4:13-19

34. Thrane PS, Rognum TO, Brandtzaeg P 1991 Ontogenesis of the secretory immune system and innate defence factors in human parotid glands. Clin Exp Immunol $86: 342-348$

35. Thrane PS, Rognum TO, Brandtzaeg P 1994 Up-regulated epithelial expression of HLA-DR and secretory component in salivary glands: reflection of mucosal immunostimulation in sudden infant death syndrome. Pediatr Res 35:625-628

36. Vege A, Rognum TO 2004 Sudden infant death syndrome, infection and inflammatory responses. FEMS Immunol Med Microbiol 42:3-10

37. Opdal SH, Rognum TO 2004 The sudden infant death syndrome gene: does it exist? Pediatrics 114:e506-e512 